\title{
Numerical Analysis of the Stability of Deep Buried Roadway under Mining Disturbance
}

\author{
WANG Yun-ping ${ }^{1,}$, ZHAO De-shen ${ }^{2, b^{*}}$ \\ ( 1.Key Laboratory of Liaoning Province for Prediction \& Control on Complicated Structure System, \\ Dalian University, Dalian 116622, China ) \\ a zhaodeshen@dlu.edu.cn , bWangYunPingJG211@163.com
}

\begin{abstract}
Keywords: high pore water pressure; deep mining; surrounding rock stability; distribution laws of water pressure

Abstract. A two dimensional finite element model is established to simulate the effect of pore water pressure on stability of surrounding rock of roadway of soft rocks and the distribution laws of water pressure during coal mining, according to the engineering geological data. Simulation results show that, the high pore water pressure region is appeared around the working surface and open-off cut and its range and values are gradually expanded, along with the increase of goaf area. So that, the dangerous area of the water burst of roof of working face is enlarged. At the advancing of working face, the pore water pressure presents the trend of high at both ends and low in the middle, and according with the saddle type damage area above the working surface. This study provided a theoretical basis for the coal mine security mining and disaster prevention and mitigation.
\end{abstract}

\section{Introduction}

With the development of modern mining technology and the increase of the demand for mineral resources, the coal mining is gradually entering the deep underground [1-2], which leads to coal seam conditions continue to deteriorate, and the maintenance of coal mine roadway and the surrounding rock control are more and more difficult. The small deformation of hard rock in the shallow stress state is often performed large deformation or failure of surrounding rock under the condition of deep high stress [3-4]. In this paper, a two-dimensional finite element model is established to simulate the effect of pore water pressure on stability of surrounding rock of roadway of soft rocks and the distribution laws of water pressure during coal mining, based on the results of previous studies.

\section{Establishment of numerical model}

\subsection{Basic assumption}

Because of the complexity of the formation and the geological structure, it is impossible to reflect the actual situation in the process of numerical simulation. Therefore, it is needed to simplify the actual situation. The numerical simulation is simple but not distorted:

(1) The same rock is considered as homogeneous isotropic medium;

(2) Ignoring the influence of the interface of adjacent rock;

(3) Fluid is in accord with Darcy's law;

(4) The model is simplified as a plane strain problem.

\subsection{Computational model and boundary conditions}

The dimensions of the model are as follows: the total height of the model is $947.58 \mathrm{~m}$, under the direction of Z; taking into account the full impact of mining, the computer calculation speed and other factors, to get the maximum advancing dimension of the working face is $795 \mathrm{~m}$, and the boundary dimension is $280 \mathrm{~m}$, so the length of the direction of $\mathrm{Y}$ is $1355 \mathrm{~m}$. Figure 1 is the picture of model grid division. 


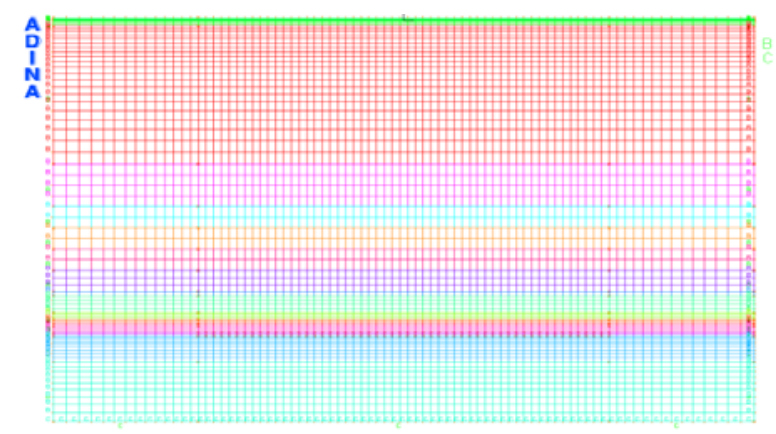

Fig.1 The computing model grid divisions

\section{Select the mechanical parameters of rock mass}

According to the rock mechanics parameters manual selecting the physical mechanics and hydraulic parameters of different coal rocks are listed in table 1.

Tab.1 Coal petrography hydraulic parameter of working face

\begin{tabular}{lcccccccc}
\hline Lithology & $\begin{array}{c}E \\
\mathrm{GPa}\end{array}$ & $v$ & $\begin{array}{c}P \\
\mathrm{~g} / \mathrm{cm}^{3}\end{array}$ & $\begin{array}{c}\Phi \\
{ }^{2}\end{array}$ & $\begin{array}{c}C \\
\mathrm{MPa}\end{array}$ & $\begin{array}{c}\sigma_{\mathrm{t}} \\
\mathrm{MPa}\end{array}$ & Porosity & $\begin{array}{c}\text { Porosity } \\
\mathrm{m}^{3} . \mathrm{day} / \mathrm{kg}\end{array}$ \\
\hline The Quaternary & 0.55 & 0.36 & 2.09 & 31.7 & 0.06 & 0.45 & 0.42 & $1.32 \times 10-5$ \\
Sandstone & 1.7 & 0.3 & 2.227 & 45 & 1.19 & 0.23 & 0.3 & $5.29 \times 10-6$ \\
Sandstone & 0.8 & 0.28 & 2.458 & 41 & 1.28 & 0.23 & 0.3 & $5.25 \times 10-6$ \\
Sand shale & 1.7 & 0.25 & 2.247 & 39 & 1.76 & 1.02 & 0.15 & $8.81 \times 10-8$ \\
Sand shale & 1.8 & 0.34 & 2.458 & 41 & 1.28 & 1.02 & 0.18 & $8.81 \times 10-8$ \\
Sand shale & 18 & 0.33 & 2.440 & 38 & 1.65 & 1.02 & 0.16 & $8.78 \times 10-8$ \\
Mudstone & 1.5 & 0.27 & 2.47 & 38 & 0.39 & 0.29 & 0.4 & $8.81 \times 10-9$ \\
Oil shale & 2.1 & 0.33 & 2.16 & 41.8 & 0.23 & 0.32 & 0.15 & $8.35 \times 10-6$ \\
Coal seam & 1.1 & 0.29 & 1.3 & 39.8 & 0.2 & 0.22 & 0.4 & $2.64 \times 10-5$ \\
Conglomerate & 2.8 & 0.26 & 2.39 & 38.8 & 0.67 & 0.68 & 0.3 & $8.81 \times 10-3$ \\
Conglomerate & 3.19 & 0.33 & 2.48 & 42.4 & 0.76 & 0.57 & 0.3 & $8.81 \times 10-3$ \\
\hline
\end{tabular}

\section{Numerical simulation}

\subsection{Vertical stress field analysis}

After coal mining, the balance of the original rock stress is destroyed, causing the overlying rock stress redistribution. Figure 2 and Figure 3 show the distribution laws of the vertical stress field of the overlying rock when the working surface is pushed to $60 \mathrm{~m}, 135 \mathrm{~m}$, which we can see that: the front of coal wall will have a low bearing stress zone, due to the goaf area surrounding rock stress release, that because of the strength of coal seam is reduced, the pressure will be transferred to the interior of the coal seam, the redistribution of the stress in the depth of the coal seam gradually increased and reached the peak stress. The magnitude of the peak stress is not only affected by the depth of mining, but also by the mining area and surrounding rock strength and other factors, and finally with the advancing of the working surface the vertical stress slowly tends to the original rock stress.

In the initial stage, the disturbance range of overlying rock is small, and the range and intensity of mining disturbance is increasing along with the advancing of mining. The vertical stress distribution as show in Figure 2, when the working face advancing 60m: in the coal seam roof strata, a number of parabola-shape stress zones were produced, and the vertical stress field basically symmetrical distribution take the goaf area as the center. In the stress arch of goaf area the stress of the roof upward gradually increasing, the floor is just the opposite. Stress concentration phenomenon be produced in the front and back of the goaf area, formation the high stress area of the "Butterfly". The peak stress is about $36.9 \mathrm{MPa}$, and the stress coefficient is 2.2 . 


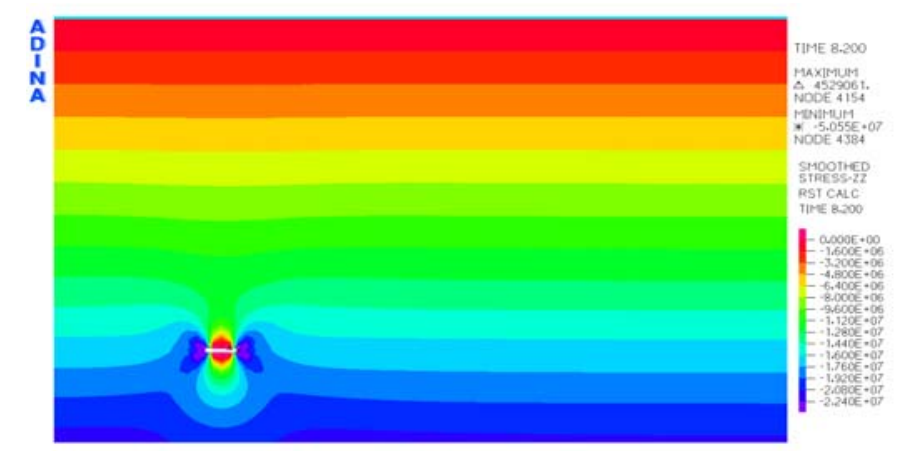

Fig. 2 Vertical stress field distribution promoting $60 \mathrm{~m}$ along strike of working face

With the advancing of the working surface, the influence range of overburden rock has been broadened. Figure 3 shows the vertical stress field distribution promoting $135 \mathrm{~m}$ along strike of working face, which can be seen that: the stress of the roof of the goaf area is changed from the compression stress to tensile stress, a large range of stress arch structure is formed in the overlying strata, and the high stress area of the "Butterfly" is also enlarged, the peak stress is about 54.3MPa, and the concentration stress coefficient is 3.12 times.

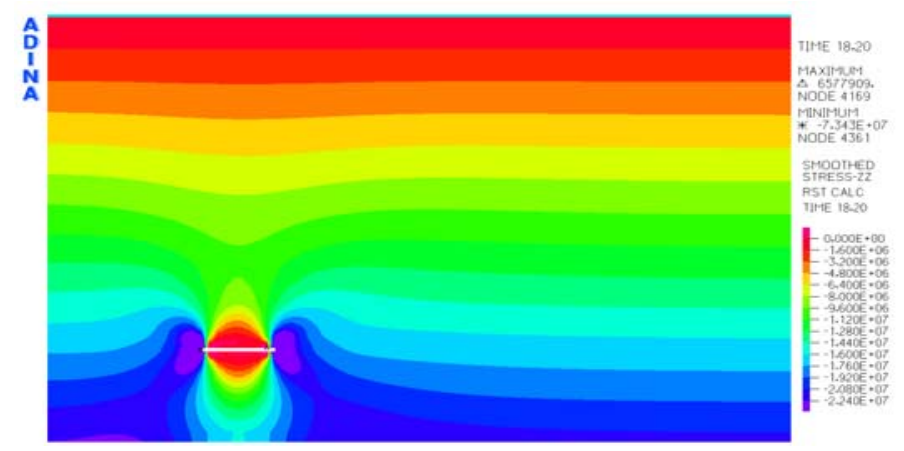

Fig. 3 Vertical stress field distribution promoting 135m along strike of working face

\subsection{Pore water pressure analysis}

The existence of pore water pressure decreases the overburden rock strength, and the more pore water pressure, the more the rock strength decreases, and then the deformation of the overlying strata is more. Figure 4 is the Pore water pressure distribution field promoting $60 \mathrm{~m}$ along strike of working face and figure 5 is the pore water pressure distribution field promoting $135 \mathrm{~m}$ along strike of working face. According to the figures, we know there rising a elevated area of pore water pressure near the working face, this is due to the excavation of the goaf area, which makes the tensile and plastic changes near the working face, so that formation the crack and improvement the permeability. Along with the advancing of the working surface, the high pore water pressure area in front of the working face was more forward, the overlying strata in the middle part of the mining area are compacted, the crack is closed, and the permeability is decreased, once the crack is completely closed, the pore water pressure disappears.

The figure 4 is the pore water pressure distribution field promoting $60 \mathrm{~m}$ along strike of working face, which can be seen that: in the oil shale at the top of the mining area the pore water pressure increases, the maximum pore water pressure 11.24MPa. According to the effective stress law of Terzaghi and Mohr-Coulomb criterion, the pore water pressure of this part will increase more and more, and easier formation the failure zone, that is consistent with failure zone of "Saddle shaped" advancing $60 \mathrm{~m}$ along strike of working face. 


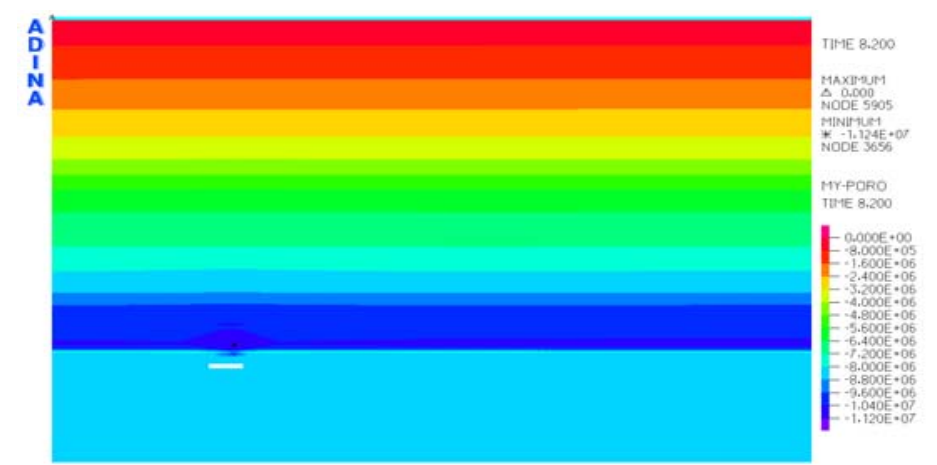

Fig. 4 Pore water pressure distribution field promoting 60m along strike of working face

The figure 5 is pore water pressure distribution field promoting $135 \mathrm{~m}$ along strike of working face, which can be seen that: enlarged region of pore water pressure has extend upward to about $31 \mathrm{~m} \sim 66 \mathrm{~m}$ above goaf of coal mine, the maximum pore water pressure is $11.86 \mathrm{MPa}$, causing this part of the rock mass strength to reduce formation the damaged area. This is consistent with the failure height on the edge of Open-off Cut reached 42m advancing 135m along strike of working face.

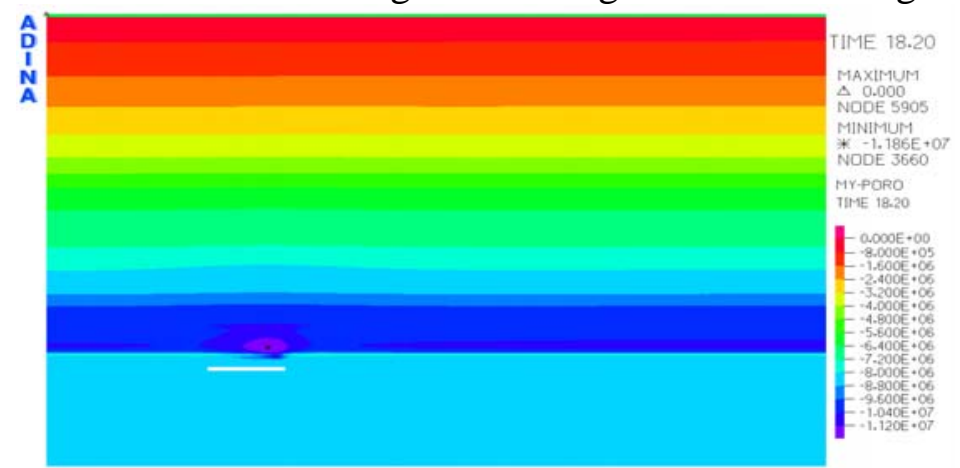

Fig. 5 Pore water pressure distribution field promoting 135m along strike of working face

Figure 6 shows the change relationship of the pore water pressure of coal seam roof along with the distance from the working surface. From the figure can be seen that stress redistribution of pore water pressure caused by mining disturbance. Along the direction of the coal seam to see, the high pore water pressure area appeared above the goaf of coal mine, the high pore water pressure changes from small to large first and then return to the initial state in the working face, when the coal seam excavation $60 \mathrm{~m}, 135 \mathrm{~m}, 270 \mathrm{~m}$ and $405 \mathrm{~m}$. The pore water pressure peaked at the both sides, and the intermediate elevations were sunk, two maximum values were appeared in the $45 \mathrm{~m}$ of the open-off cut and the working face, and the minimum value appeared in front of the open-off cut $255 \mathrm{~m}$, the pore water pressure is back to the original state, which is consistent with failure zone of "Saddle shaped". Along with the advance of the working face, the maximum pore water pressure was 8.3MPa, 8.5 MPa, $9 \mathrm{MPa}$, 9.5 $\mathrm{MPa}, 10 \mathrm{MPa}, 10.7, \mathrm{MPa}$ and $11.6 \mathrm{MPa}$ respectively, showing an increasing trend, when the coal seam excavation $540 \mathrm{~m}, 675 \mathrm{~m}$ and $795 \mathrm{~m}$. 


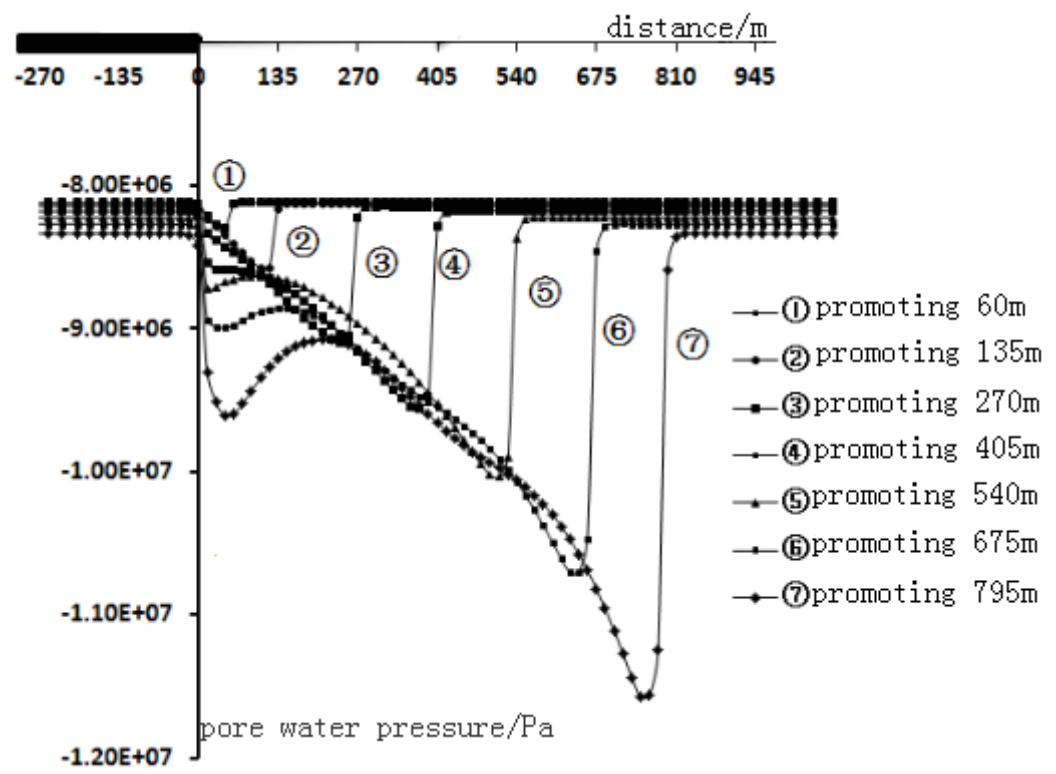

Fig. 6 Relation between pore water pressures of coal seam immediate roof and advaneing distance along strike of working face

\section{Summary}

1) The front of coal wall will have a low bearing stress zone, due to the goaf area surrounding rock stress release, that because of the strength of coal seam is reduced, the pressure will be transferred to the interior of the coal seam, the redistribution of the stress in the depth of the coal seam gradually increased and reached the peak stress. The magnitude of the peak stress is not only affected by the depth of mining, but also by the mining area and surrounding rock strength and other factors, and finally with the advancing of the working surface the vertical stress slowly tends to the original rock stress.

2) Along with the advancing of the working surface, the high pore water pressure area in front of the working face was more forward, the overlying strata in the middle part of the mining area are compacted, the crack is closed, and the permeability is decreased, once the crack is completely closed, the pore water pressure disappears.

\section{Acknowledgements}

The author would like to thank the financial support by the National Natural Science Foundation of China (Grant No. 51274051).

\section{References}

[1] $\mathrm{Yu}$ Baohua, Zhu guard, Xu Jialin. A numerical simulation of the characteristics of surface subsidence in deep mining, [J]. mining and safety engineering, 2007,04:422-426

[2] Xu Naizhong, Wang Bin, Qi Yongchuan. Deep mining surface subsidence prediction [J]. Journal of Mining \& Safety Engineering, 2006,01:66-69.

[3] Meng Qingbin, Han Li Jun, Wei Guo Qiao, linden Pavilion, Lv Yanxin. Deep department high should stress soft rock roadway deformation and failure characteristics [J]. Mining \& Safety Engineering Journal, 2012,04:481-486.

[4] Zeng Liang. Research on stability of surrounding rock in deep mining gateway [D]. Chongqing University, 2010 